\title{
Sistem Informasi Simpan Pinjam di Koperasi Pendidikan Wonogiri
}

\author{
Hanifa Salsabila*1, Endah Sudarmilah ${ }^{2}$ \\ 1,2Informaika/Universitas Muhammadiyah Surakarta \\ shalsabhela@gmail.com¹,Endah.Sudarmilah@ums.ac.id²
}

\begin{abstract}
Abstrak
Koperasi merupakan organisasi yang ada dibidang kesejahteraan, dengan tujuan menunjang perekonomian masyarakat. Koperasi simpan pinjam yaitu koperasi yang menyediakan jasa untuk meminjam uang dan menyimpan uang. Permasalahan yang ada pada Koperasi Simpan Pinjam Pendidikan Wonogiri saat ini adalah ketiadaan support teknologi untuk sistem informasinya. Pelayanan di koperasi ini meliputi proses transaksi simpan pinjam, pembayaran angsuran, dan pengolahan data anggota yang masih menggunakan pencatatan secara manual. Hal ini dapat menimbulkan rentan adanya kesalahan dalam proses penginputan data. Dari permasalahan tersebut Koperasi Pendidikan Wonogiri ini membutuhkan suatu sistem informasi dengan tujuan untuk memudahkan yang awalnya menggunakan non-komputerisasi menjadi komputerisasi. Dengan menggunakan metode waterfall dan diaplikasikan dalam bentuk aplikasi berbasis web ini dirancang menggunakan bahasa pemrograman PHP dan di simpan dalam sebuah database MySQL. Sistem yang dibuat diharapkan dapat membantu pengguna khususnya anggota koperasi dan petugas koperasi dalam melakukan transaksi simpan pinjam.
\end{abstract}

Kata Kunci: Koperasi, Simpan Pinjam, Sistem Informasi, Sistem Informasi berbasis Web

\begin{abstract}
Cooperative is one form of organization in the field of welfare, to support the economy of the community, especially the low economic community and middle economic community. Savings and loan cooperatives are cooperatives that provide money loans and for a place to save money. The problem with Wonogiri Education Savings and Credit Cooperatives at the moment is the lack of technological support for the information system. Transaction services that are currently running are still done manually, it can be seen from the process of savings and loan transactions, installment payments, and data processing members. It is unavoidable that manual recording is prone to errors, so the Wonogiri Education Cooperative needs a software information system that replaces the work that was originally still manually being computer-based. By using the waterfall method and applied in the form of a web-based application it is designed using the PHP programming language and stored in a MySQL database. The system is expected to help users, especially cooperative members and cooperative officers, in conducting savings and loan transactions.
\end{abstract}

Keywords: Cooperatives, Information Systems, Savings and Loans, Web-based Information Systems

\section{Pendahuluan}

Koperasi merupakan sebuah lembaga usaha yang dimiliki dan dijalankan oleh anggotanya untuk memenuhi kebutuhan bersama baik di bidang ekonomi, sosial ataupun budaya. Koperasi dijalankan dengan asas kekeluargaan [1]. Tujuan koperasi untuk mencapai keuntungan bersama, bukan perseorangan [2].

Koperasi Pendidikan (Kopendik) Wonogiri merupakan salah satu organisasi sebagai unit kesejahteraan anggota, dalam organisasi ini beranggotakan para pegawai dinas yang ada di kabupaten wonogiri. Koperasi ini menangani sektor simpan pinjam, yaitu memberikan pelayanan jasa simpan pinjam pada anggota maupun petugas koperasi. Adanya koperasi simpan pinjam ini dapat membantu anggota untuk menyimpan uang dan melakukan pinjaman dengan bunga yang rendah [3].

Kegiatan simpan pinjam yang ada di Kopendik Wonogiri masih dilakukan secara manual atau belum adanya komputerisasi sehingga dapat menimbulkan masalah dalam input, proses 
maupun output. Proses transaksi seperti penghitungan tabungan simpanan tiap anggota, penghitungan pinjaman angsuran, dilakukan dan dicatat secara manual dan belum tertata rapi. Kondisi ini menimbulkan permasalahan yang kemungkinan terjadi adanya kesalahan penulisan dan pencatatan serta lamanya waktu dalam proses pencarian data [4].

Cara yang tepat untuk mengatasi permasalahan ini dengan menggunakan komputerisasi [5]. Oleh karena itu dibuatlah suatu sistem informasi berbasis web yang terintegrasi untuk menggantikan pekerjaan yang awalnya masih secara manual menjadi terkomputerisasi [6]. Sistem informasi ini diharapkan dapat mempermudah dan mengatur jalannya koperasi untuk kedepannya [7].

Metode perancangan sistem menggunakan metode waterfall, dengan pemodelan ini menyediakan pendekatan alur hidup yang berurutan dimulai dari analisis, desain, pengkodean, pengujian, dan tahap pendukung [5]. Dalam proses pengkodean program, menggunakan bahasa pemrograman PHP dengan basis data MySQL [8]. Manfaat yang diharapkan dalam penelitian ini yaitu untuk meningkatkan kinerja dalam proses transaksi simpan pinjam di Koperasi Pendidikan Wonogiri sehingga dapat memberikan solusi kecepatan, ketepatan, dan keakuratan transaksi simpan pinjam agar mendapatkan hasil yang optima [9].

\section{Metode Penelitian}

Permasalahan yang ada pada Koperasi Pendidikan Wonogiri saat ini adalah ketiadaan support teknologi untuk sistem informasinya. Oleh karena itu menjadi faktor pendorong bagi peneliti untuk melakukan penelitian dengan metode penelitian yang digunakan adalah tahapan metode waterfall.

Metode waterfall meliputi analisis, design, coding, testing, dan maintenance. Tahap analisis ditentukan melalui konsultasi dengan user sistem dimana meliputi persyaratan, pelayanan, batasan dan tujuan sistem, kemudian didefinisikan spesifikasi sistem secara rinci [10]. Design merupakan proses perancangan arsitektur sistem secara keseluruhan dengan membagi kebutuhan-kebutuhan menjadi sistem informasi atau perangkat keras [7]. Coding merupakan tahap implementasi dimana sistem pertama kali dikembangkan. Testing merupakan pengujian unit untuk menguji setiap modul dengan tujuan mengetahui setiap modul berjalan dengan baik atau tidak [7]. Maintenance merupakan tahap pemeliharaan dimana sistem mengalami perubahan ketika sudah dikirimkan ke user. Perubahan bisa terjadi karena adanya kesalahan yang muncul dan tidak terdeteksi saat pengujian [5]. Metode penelitian yang di gunakan dapat dilihat pada Gambar 1.

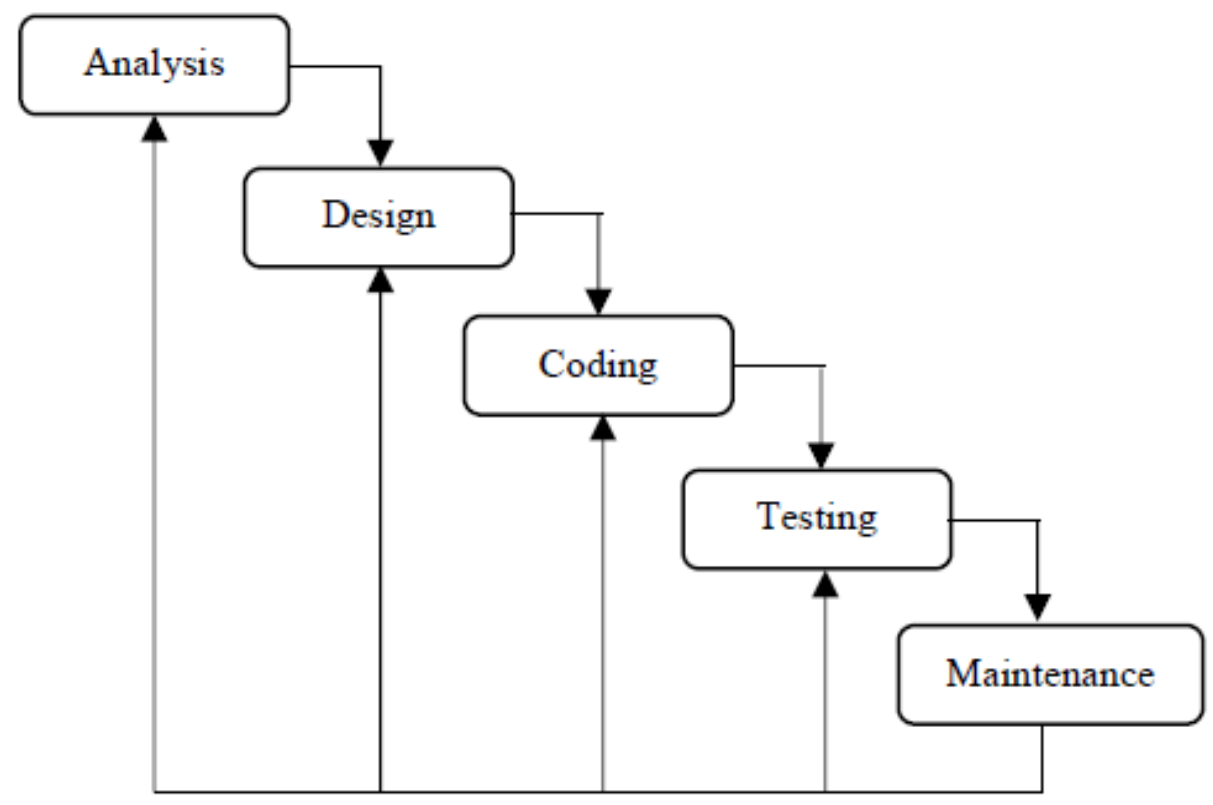

Gambar 1. Diagram Alur Penelitian dengan Metode Waterfall

REPOSITOR, Vol. 2, No. 5, Mei 2020: 541-552 


\subsection{Analisis Kebutuhan \\ 2.1.1 Kebutuhan Data}

Dalam proses pembuatan sistem, diperlukan adanya pengumpulan data yang dibutuhkan, berikut ini cara penulis dalam proses mengumpulkan pengambilan data.

1. Dokumen

Penulis melakukan pengumpulan data dengan mempelajari dokumen-dokumen yang berkaitan. Hal ini dilakukan dengan tujuan untuk mengetahui proses kerja simpan pinjam pada Koperasi Pendidikan Wonogiri.

2. Pengamatan (Observation)

Kegiatan observasi ini melakukan pengamatan secara langsung dengan mendatangi koperasi pendidikan wonogiri. Hal ini bertujuan untuk mengetahui secara langsung mengenai sistem kerja yang ada disana.

3. Wawancara (Interview)

Wawancara dilakukan kepada pihak yang berkaitan untuk memperoleh data-data yang dibutuhkan. Dengan adanya wawancara ini untuk mengetahui kegiatan apa saja yang dilakukan, serta untuk memperoleh data yang dibutuhkan untuk merancang sistem informasi [11]. Data-data yang dibutuhkan antara lain : data anggota koperasi, data simpanan anggota koperasi, data simpanan angggota koperasi, data pinjaman anggota koperasi, data angsuran anggota koperasi.

\subsubsection{Kebutuhan Sistem}

Agar sistem dapat berjalan dengan maksimal diperlukan maka diperlukan beberapa kebutuhan sistem, diantaranya :

1. Kebutuhan Fungsional

Kebutuhan Fungsional berisikan fitur-fitur yang akan dimasukkan ke dalam sistem yang akan dibuat (1). Adapun fitur-fitur Sistem Informasi Simpan Pinjam di Koperasi Pendidikan Wonogiri ini adalah :

a) Kebutuhan Petugas : halaman login, tampilan data anggota, tampilan data simpanan, pinjaman, dan angsuran anggota, tampilan master data yang berisi laporan-laporan, tampilan edit profile, halaman logout.

b) Kebutuhan Ketua : halaman login, tampilan data petugas, tampilan data permintaan persetujuan pinjaman anggota, tampilan laporan-laporan koperasi, edit profile, halaman logout.

2. Kebutuhan Non Fungsional

Kebutuhan Non Fungsional merupakan kebutuhan yang berisi properti perilaku yang dimiliki oleh sistem [12], meliputi :

a) Operasional

- Perangkat keras: Processor type Intel(R)Core i3, Network, Optical Drive, Monitor, Keybord, Mouse, dll.

- Perangkat lunak : Windows XP/7/8, PHP/HTML, Notepad++, Internet Explorer/Mozilla Firefox, XAMPP, mySQL Server.

\subsection{Desain Sistem}

Tujuan dari tahap design adalah memberikan gambaran tentang apa yang akan dikerjakan dan bagaimana tampilan sistem yang akan dibuat. Dokumentasi yang dihasilkan dari tahap desain sistem ini antara lain perancangan Use Case Diagram, Activity Diagram, serta Entity Relationship Diagram (ERD) [3].

\subsubsection{Use Case Diagram}

Use Case Diagram adalah suatu tipe khusus yang menggambarkan secara ringkas siapa yang menggunakan sistem dan apa saja yang bisa dilakukannya [13]. Terdapat 2 actor dalam use case sistem informasi simpan pinjam ini yaitu petugas koperasi dan ketua koperasi. Petugas koperasi adalah orang yang mengelola kegiatan transaksi simpan pinjam anggota, petugas berhak untuk mengelola data anggota, data simpanan, data pinjaman, data angsuran, serta mengelola laporan dari master data. Ketua koperasi adalah orang yang memimpin suatu koperasi, ketua koperasi berhak untuk mengelola data petugas koperasi, menyetujui permintaan persetujuan pinjaman dari anggota, serta melihat laporan-laporan yang ada di koperasi. Berikut gambar use case diagram sistem informasi simpan pinjam di koperasi pendidikan wonogiri. Use case diagram Sistem Informasi Simpan Pinjam di Koperasi Wonogiri dapat dilihat pada Gambar 2. 


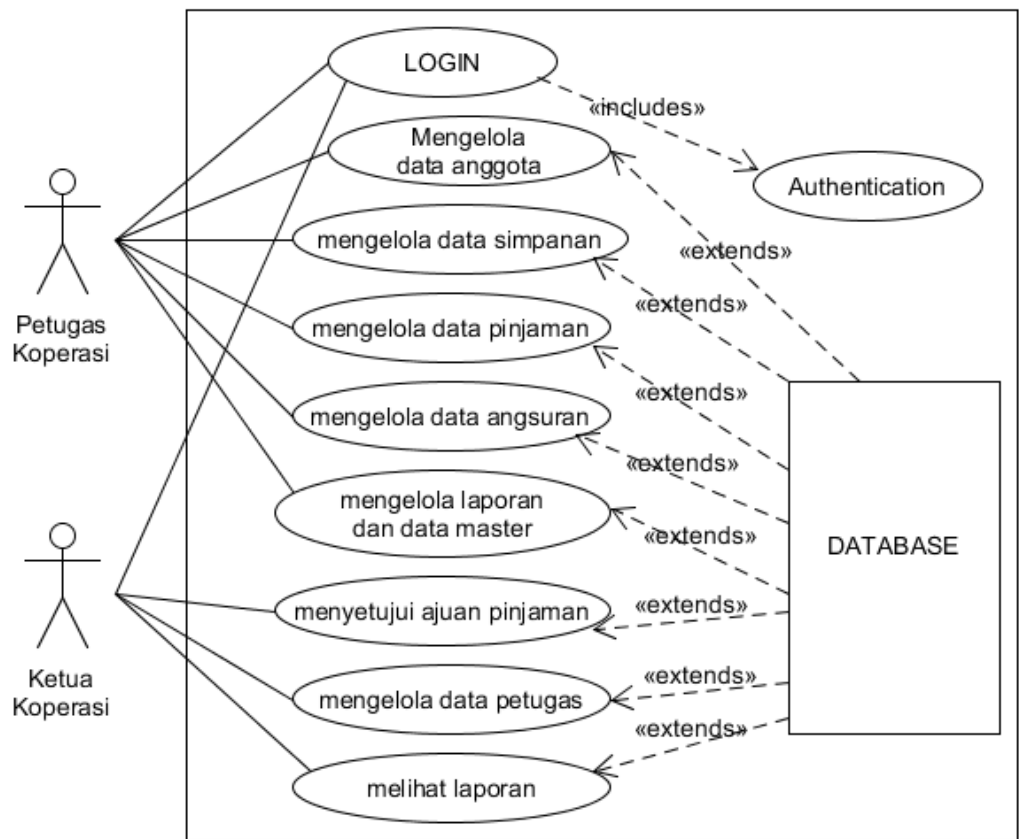

Gambar 2. Use Case Diagram Sistem Informasi Simpan Pinjam di Koperasi Pendidikan Wonogiri

\subsubsection{Activity Diagram}

Activity Diagram adalah suatu tipe khusus yang menggambarkan tentang aktifitas yang terjadi pada suatu sistem [3].

\subsubsection{Login}

Petugas koperasi dan ketua koperasi melakukan login dengan memasukaan username dan password. Jika berhasil login akan masuk ke halaman utama, jika gagal login akan menampilkan tampilan gagal login sehingga harus melakukan login kembali. Diagram activity login dapat dilihat pada Gambar 3.

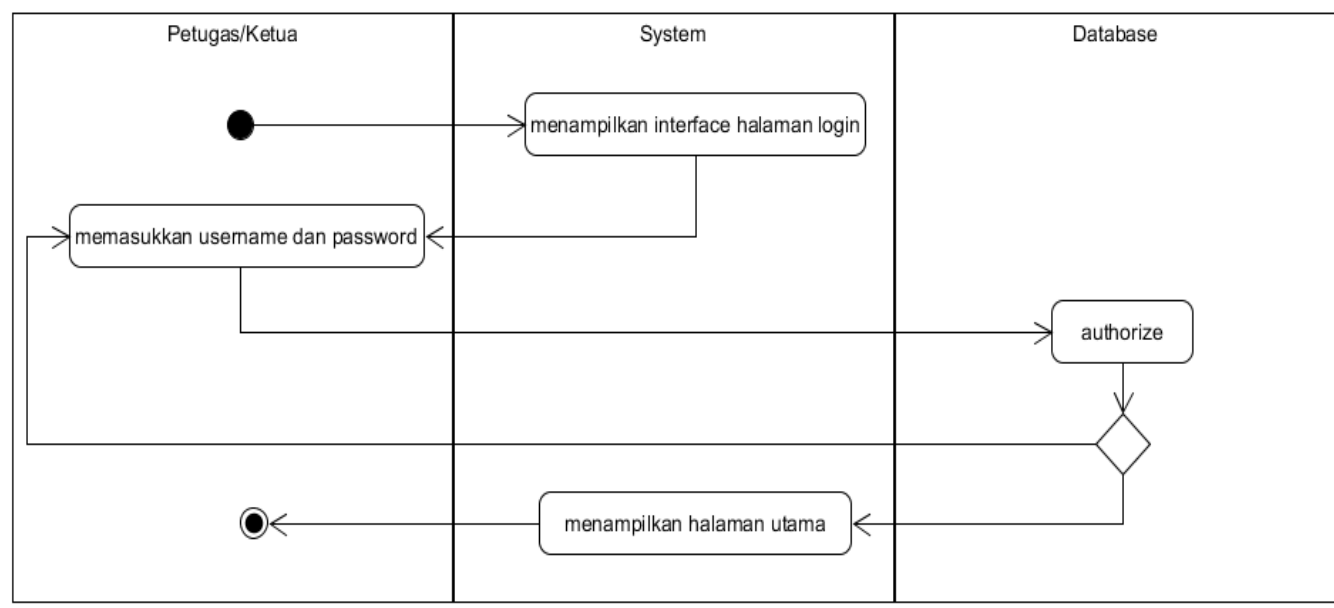

Gambar 3. Diagram Activity Login

\subsubsection{Pendaftaran Anggota Koperasi}

Calon anggota datang menemui petugas koperasi, petugas koperasi mengisikan formulir pendaftaran pada sistem, kemudian calon anggota menyerahkan uang simpanan dan uang simpanan wajib ke petugas sebagai syarat pendaftaran anggota koperasi, petugas koperasi menerima uang lalu menginputkan ke dalam sistem. Diagram activity pendaftaran anggota koperasi dapat dilihat pada Gambar 4. 


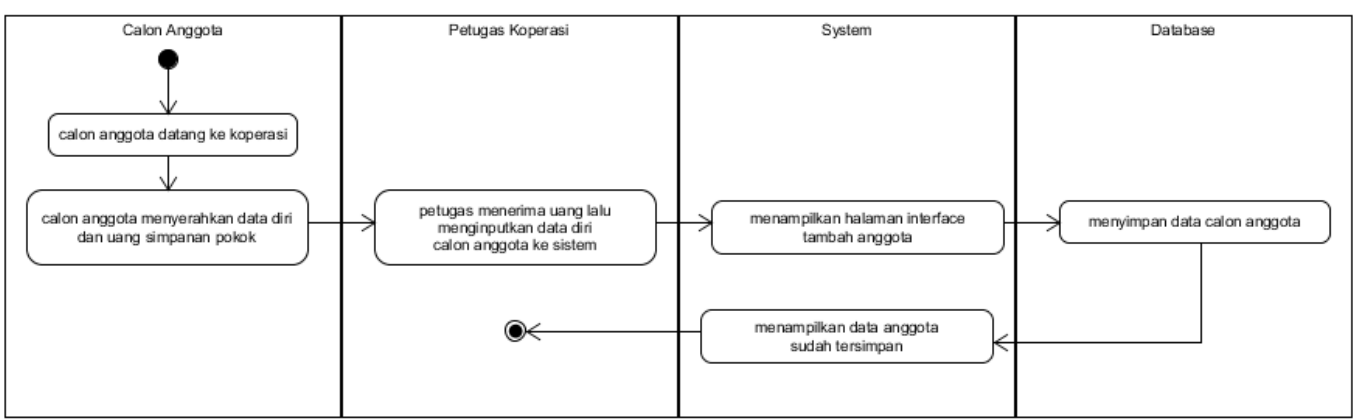

Gambar 4. Activity Diagram Pendaftaran Anggota Koperasi

\subsubsection{Proses Permintaan Peminjaman}

Anggota mengisi surat permohonan pinjaman, kemudian petugas koperasi akan memeriksa pinjaman terakhir anggota. Jika peminjaman terakhir anggota sudah memenuhi maka petugas akan menginputkan ajuan pinjaman ke dalam sistem dan menunggu persetujuan dari ketua. Ketua koperasi akan mendapatkan notifikasi pesetujuan ajuan pinjaman. Jika ketua koperasi setuju maka petugas akan membuat bukti pinjaman anggota kedalam sistem, jika koperasi tidak menyetujui petugas koperasi akan memberitahukan anggota bahwa ajuan pinjaman ditolak. Diagram activity proses permintaan pinjaman dapat dilihat pada Gambar 5 dan Gambar 6

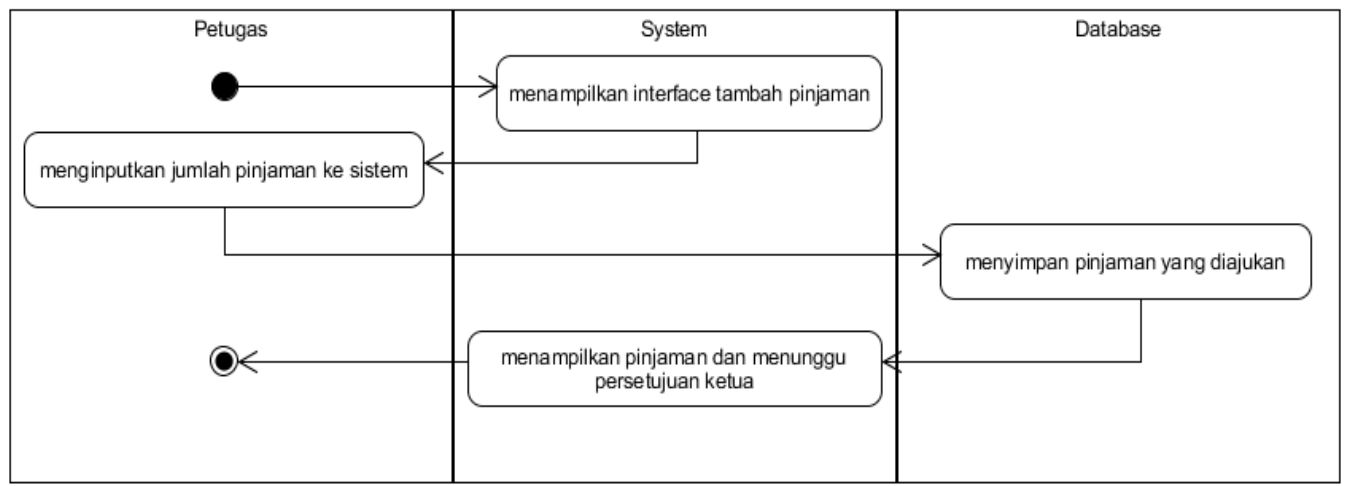

Gambar 5. Activity Diagram Proses Permintaan Pinjaman

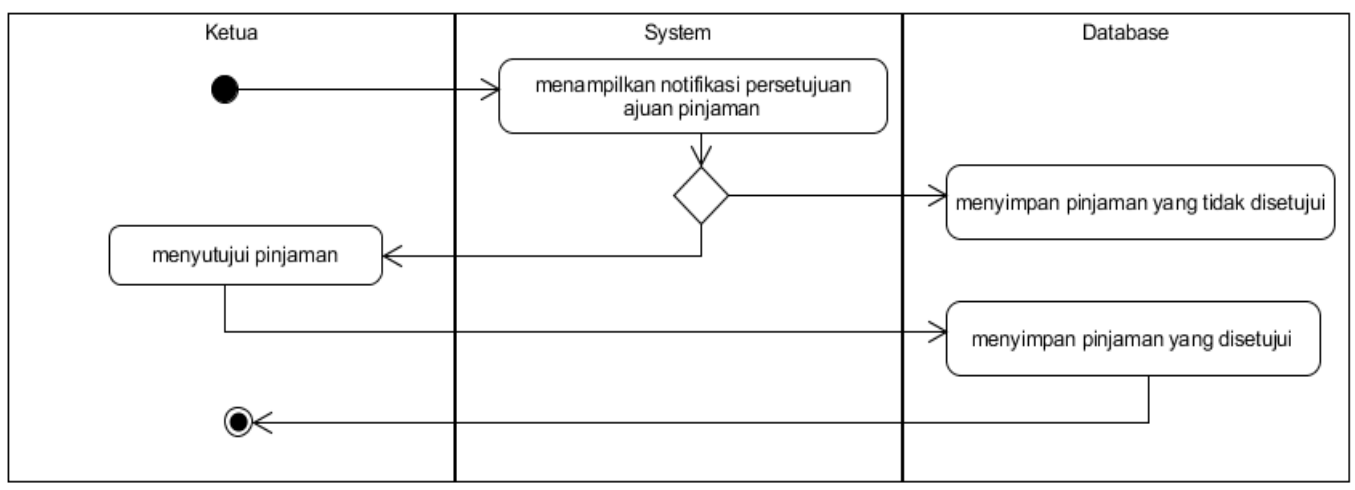

Gambar 6. Activity Diagram Proses Persetujuan Pinjaman

\subsubsection{Proses Pembayaran Angsuran}

Ketika anggota sudah mengambil pinjaman maka secara otomatis anggota akan membayar biaya angsuran per bulan. Anggota yang hendak membayar angsuran memberikan uang angsuran tersebut ke petugas koperasi, kemudian petugas koperasi membuat bukti pembayaran angsuran dan mencatat pembayaran angsuran ke dalam sistem. Diagram activity proses pembayaran angsuran dapat dilihat pada Gambar 7 . 


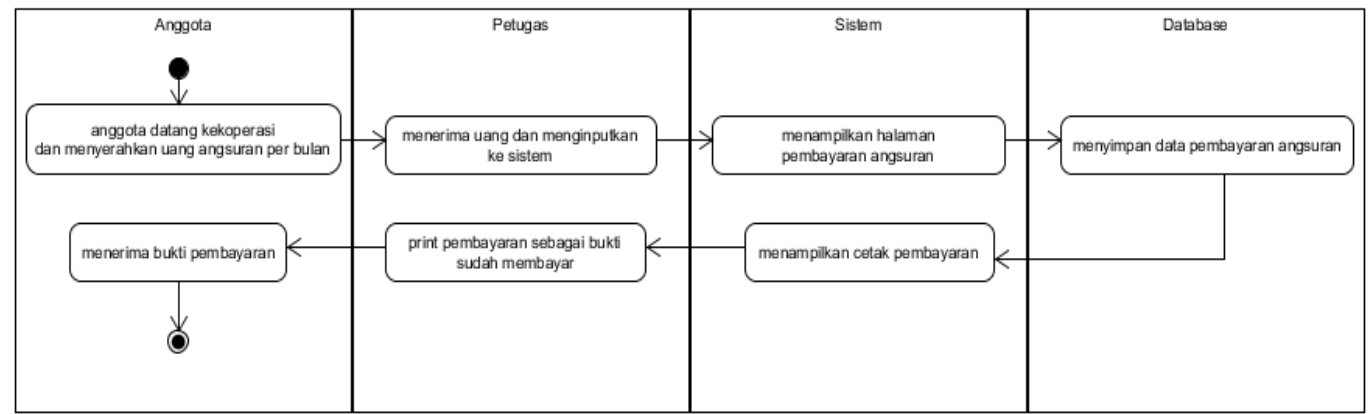

Gambar 7. Activity Diagram Proses Pembayaran Angsuran

\subsubsection{Proses Simpanan}

Anggota yang hendak melakukan simpanan datang ke koperasi menemui petugas koperasi, kemudian anggota menyerahkan sejumlah uang ke petugas koperasi, lalu petugas koperasi akan menanyakan jenis simpanan yang diinginkan oleh anggota, anggota memilih jenis simpanan, setelah memilih anggota memberitahukan jenis simpanan ke petugas koperasi, kemudian petugas koperasi akan mencatat jumlah uang yang diserahkan oleh anggota dan mencatat jenis simpanan anggota ke dalam sistem, setelah itu petugas koperasi membuat bukti simpanan dan menyerahkan bukti simpanan kepada anggota. Diagram activity proses simpanan dapat dilihat pada Gambar 8.

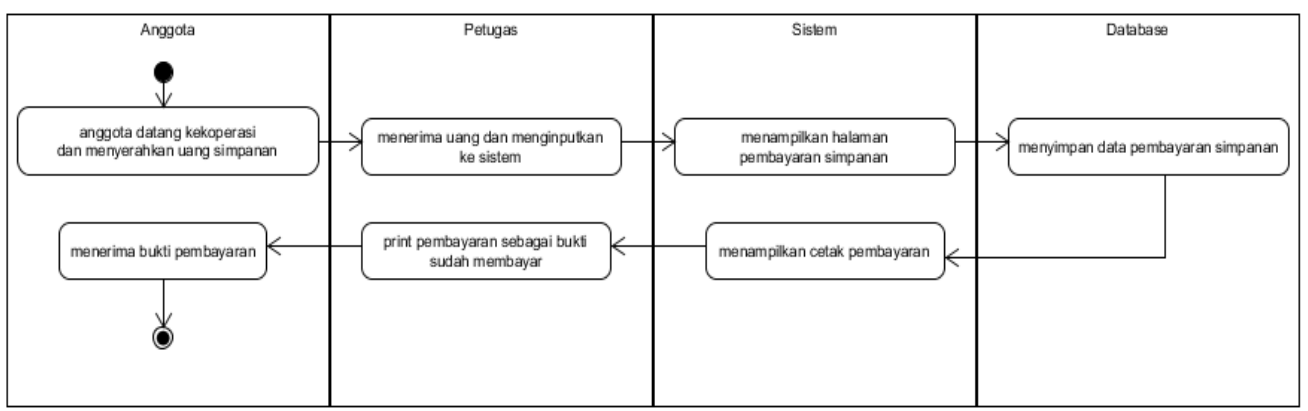

Gambar 8. Activity Diagram Proses Simpanan

\subsubsection{Entity Relationship Diagram (ERD)}

Entity Relationship Diagram adalah suatu model untuk menjelaskan entitas dan relasi yang berhubungan dalam basis data berdasarkan objek [14]. Berikut adalah ERD Sistem Informasi Simpan Pinjam di Koperasi Wonogiri dapat dilihat pada Gambar 9.
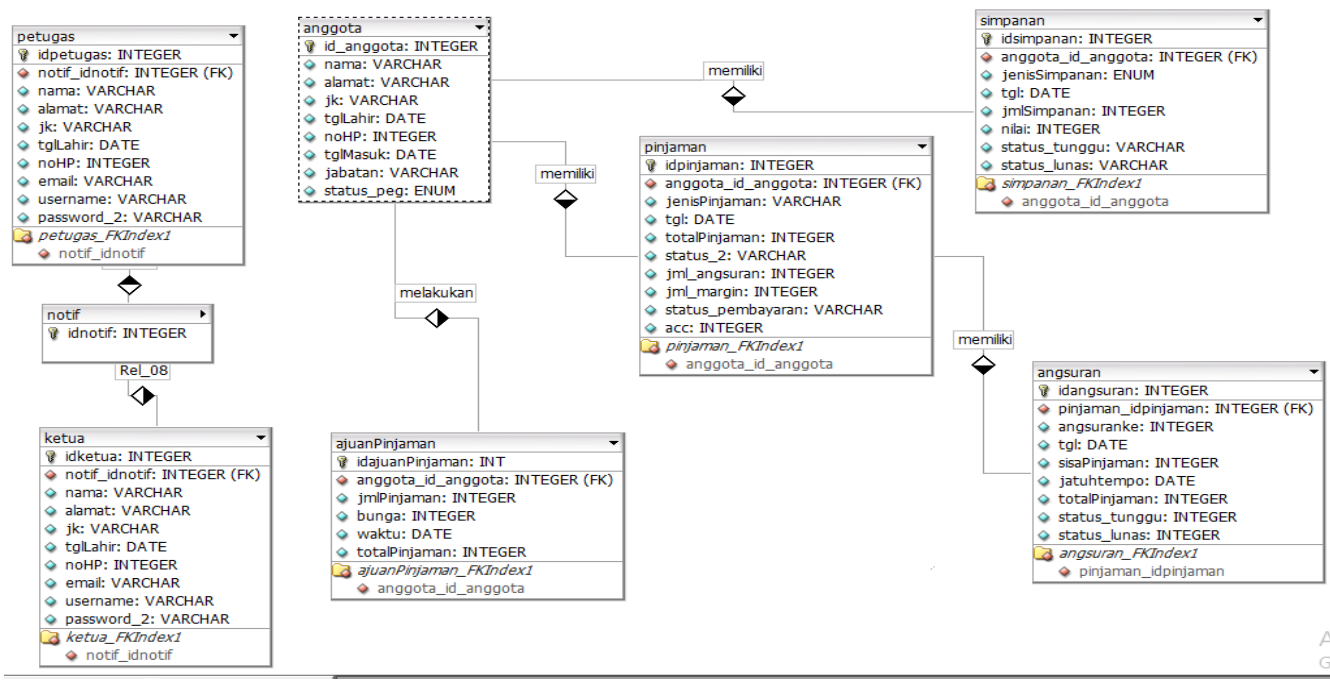

Gambar 9. Entity Relationship Diagram Koperasi Simpan Pinjam

REPOSITOR, Vol. 2, No. 5, Mei 2020: 541-552 


\subsection{Coding (Penulisan Kode Program)}

Tahap ini merupakan tahap awal dalam pembuatan sistem. Penulisan kode program merupakan tahap dimana desain diubah ke dalam bentuk perintah yang dimengerti oleh komputer dengan menggunakan bahasa pemograman. Bahasa pemrograman yang dipakai dalam penelitian ini adalah PHP dan database MySQL.

\subsection{Testing (Pengujian Program)}

Pengujian dilakukan untuk memastikan bahwa software yang dibuat telah sesuai dengan desainnya dan semua fungsi dapat dipergunakan dengan baik tanpa ada kesalahan. Testing dalam peelitian ini dilakukan menggunakan metode black-box. Black-box merupakan pengujian yang dilakukan dengan menjalankan atau mengeksekusi unit sesuai dengan proses sistem yang diinginkan [7].

\subsection{Operation and Maintenance (Pemeliharaan Program)}

Tahap ini merupakan tahap terakhir dalam metode waterfall dimana sistem dapat di implementasikan. Pemeliharaan mencakup dari perbaikan dari eror yang tidak ditemukan pada tahap pengujian sebelumnya. Pemeliharaan sistem ini dapat dilakukan oleh seorang administrator untuk meningkatkan kualitas sistem agar jauh lebik baik.

\section{Hasil Penelitian dan Pembahasan}

\subsection{Tampilan Aplikasi}

\subsubsection{Halaman Data Anggota Koperasi}

Halaman ini berisikan data anggota koperasi meliputi id anggota, nama, alamat, nomer telepon, dan lain sebagainya. Didalam halaman ini terdapat aksi detail untuk melihat semua informasi data anggota, edit untuk mengubah data anggota, dan hapus untuk menghapus data anggota. Berikut halaman data anggota dapat dilihat pada Gambar 10.

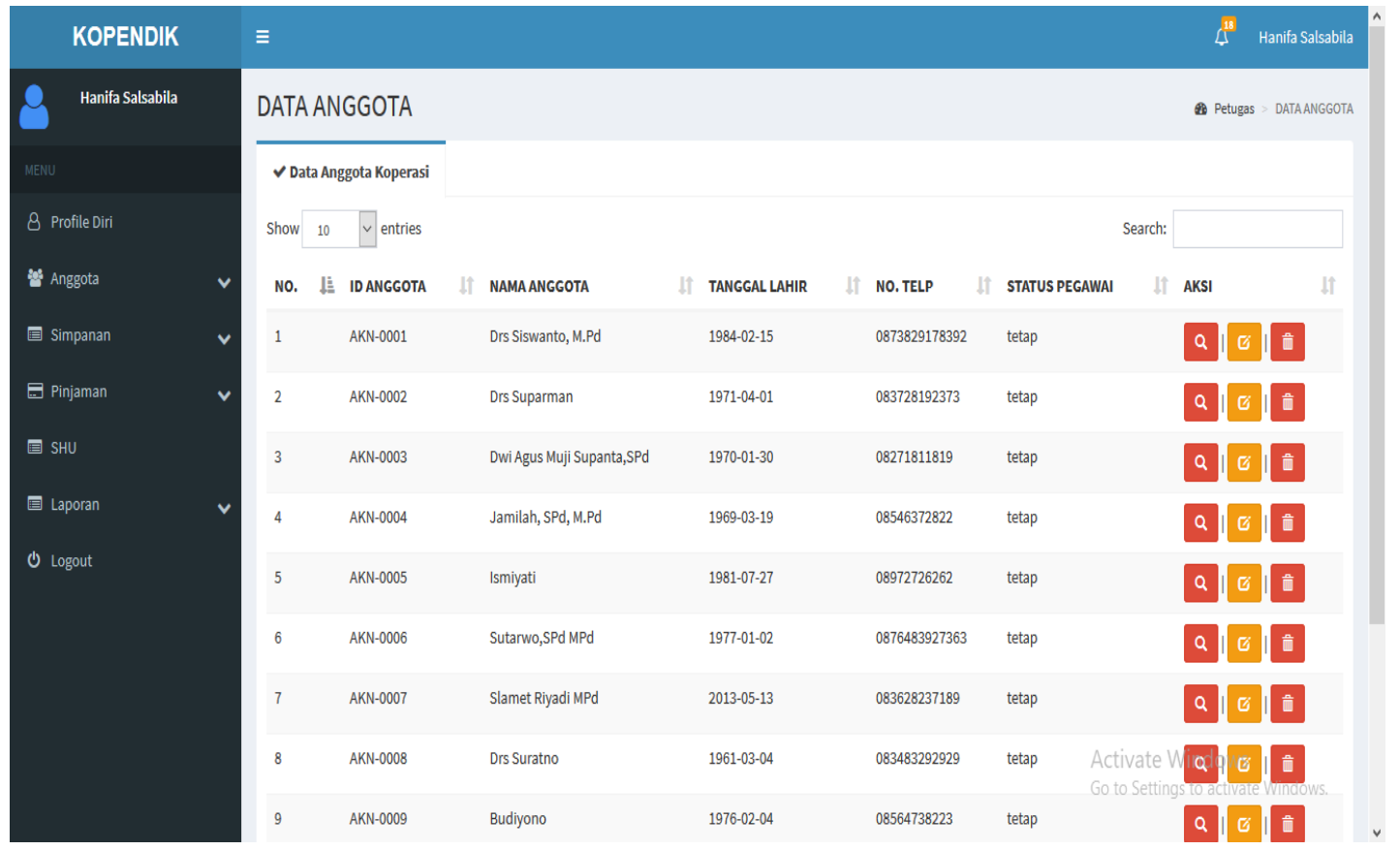

Gambar 10. Halaman Data Anggota

\subsubsection{Halaman Data Simpanan}

Halaman ini berisikan data simpanan yang telah dilakukan oleh anggota koperasi yang meliputi jumlah saldo total dari semua simpanan, tanggal simpanan, dan nama anggota. Halaman ini juga terdapat aksi yaitu tombol plus untuk menambhkan simpanan, tmbol minus untuk mengambil simpanan, dan tombol detail untuk melihat detail simpanan dan mencetak transaksi simpanan. Berikut halaman data simpanan dapat dilihat pada Gambar 11. 


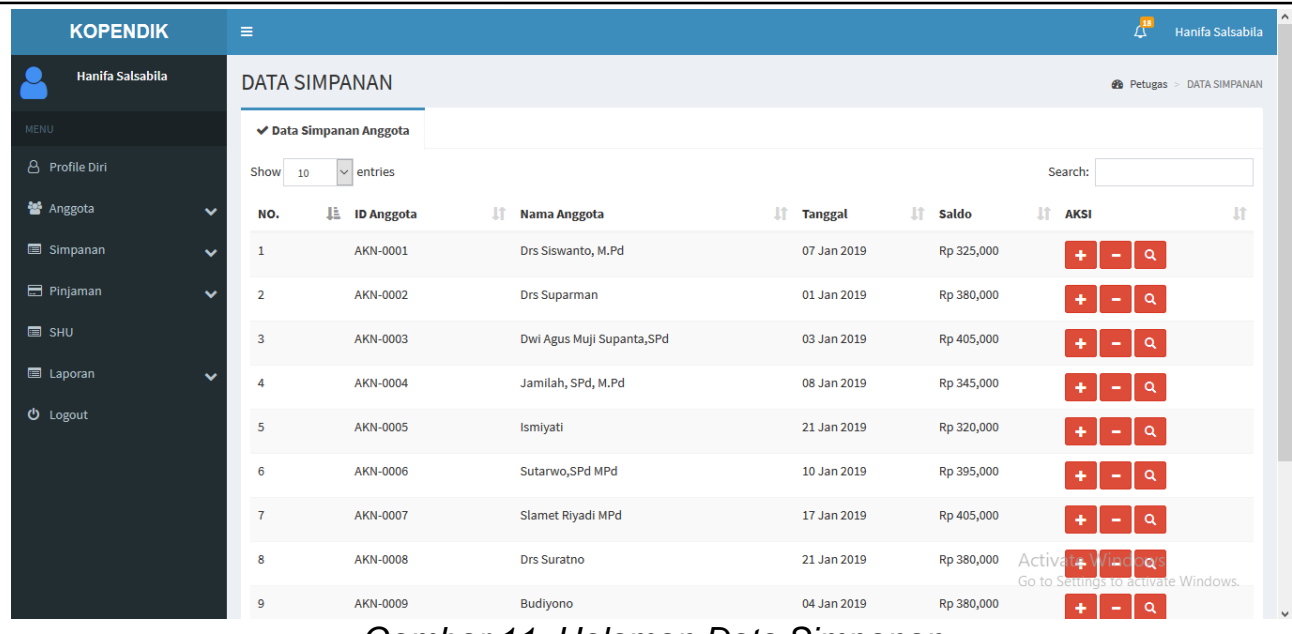

Gambar 11. Halaman Data Simpanan

\subsubsection{Halaman Data Pinjaman}

Halaman ini berisikan pinjaman anggota yang meliputi jumlah pinjaman, lama pinjaman, tanggal pinjaman, status pinjaman, nama dan id anggota. Halaman ini juga mempunyai aksi yaitu print yang berisikan rincian angsuran yang harus dibayar anggota perbulanya dan detail pinjaman yang berisikan halaman untuk membayar angsuran. Berikut halaman data pinjaman dapat dilihat pada Gambar 12 dan Gambar 13.

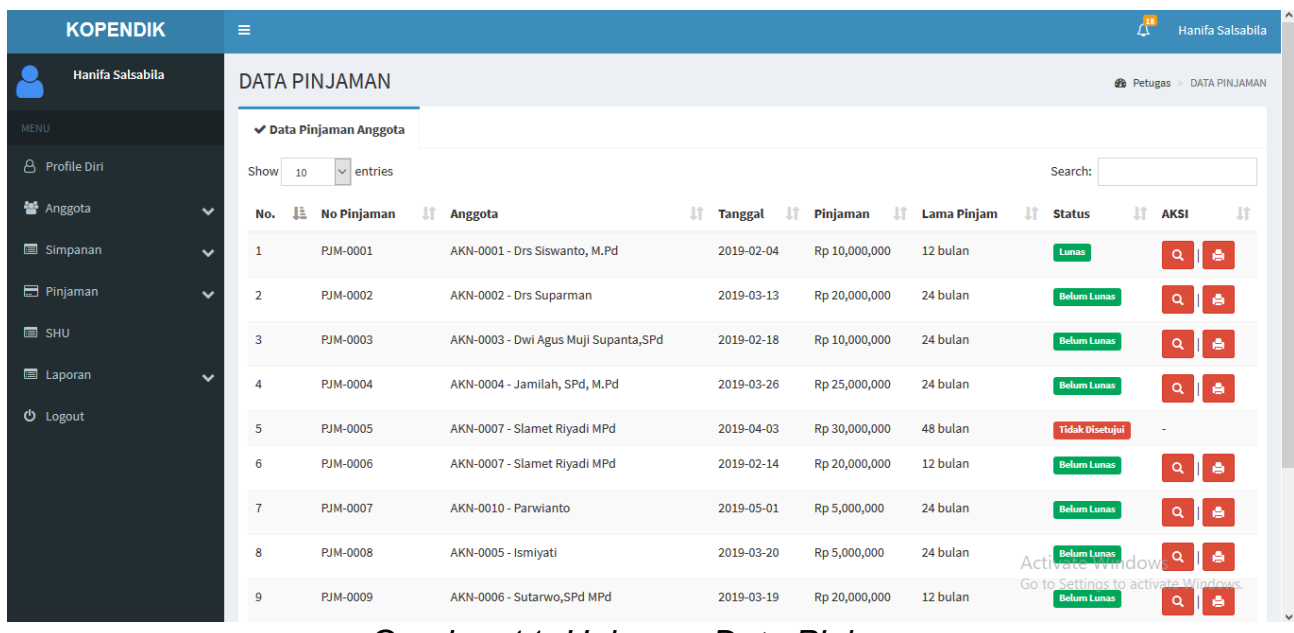

Gambar 11. Halaman Data Pinjaman

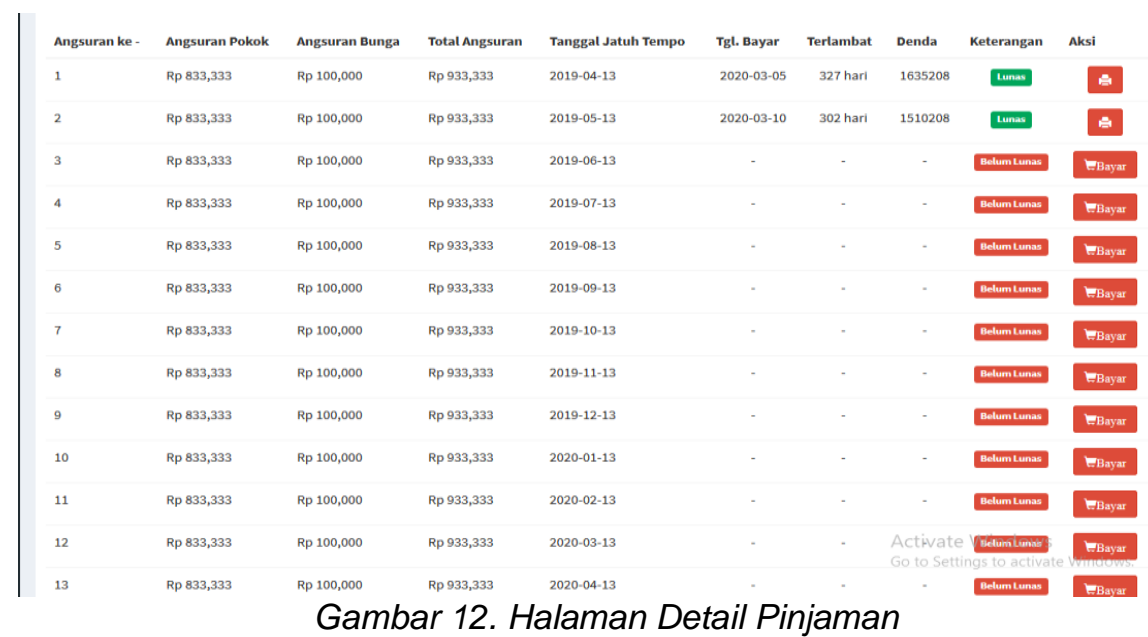

REPOSITOR, Vol. 2, No. 5, Mei 2020: 541-552 


\subsubsection{Halaman Laporan Tahunan}

Halaman ini berisikan laporan tahunan meliputi jumlah simpanan, jumlah pinjaman, shu simpanan, dan shu pinjaman per anggota. Berikut laporan dapat dilihat pada Gambar 13.

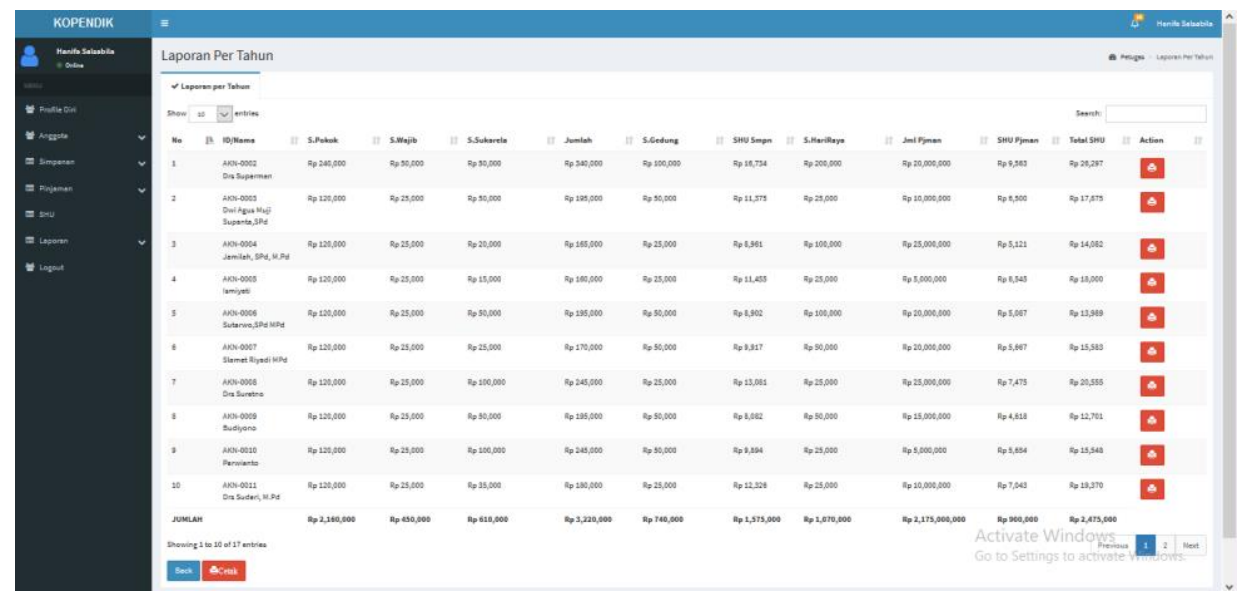

Gambar 13. Halaman Laporan Tahunan

\subsubsection{Halaman Pemberitahuan}

Halaman ini hanya terdapat di dalam hak akses ketua. Dimana ketua koperasi menyetujui pinjaman yang telah diinputkan petugas. Berikut halaman pemberitahuan dapat dilihat pada Gambar 14 dan Gambar 15.

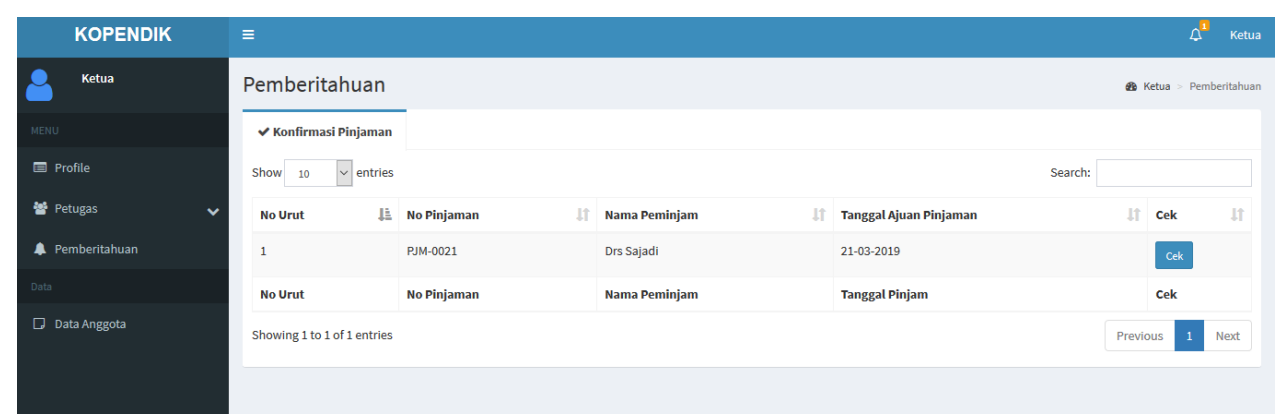

Gambar 14. Halaman Pemberitahuan

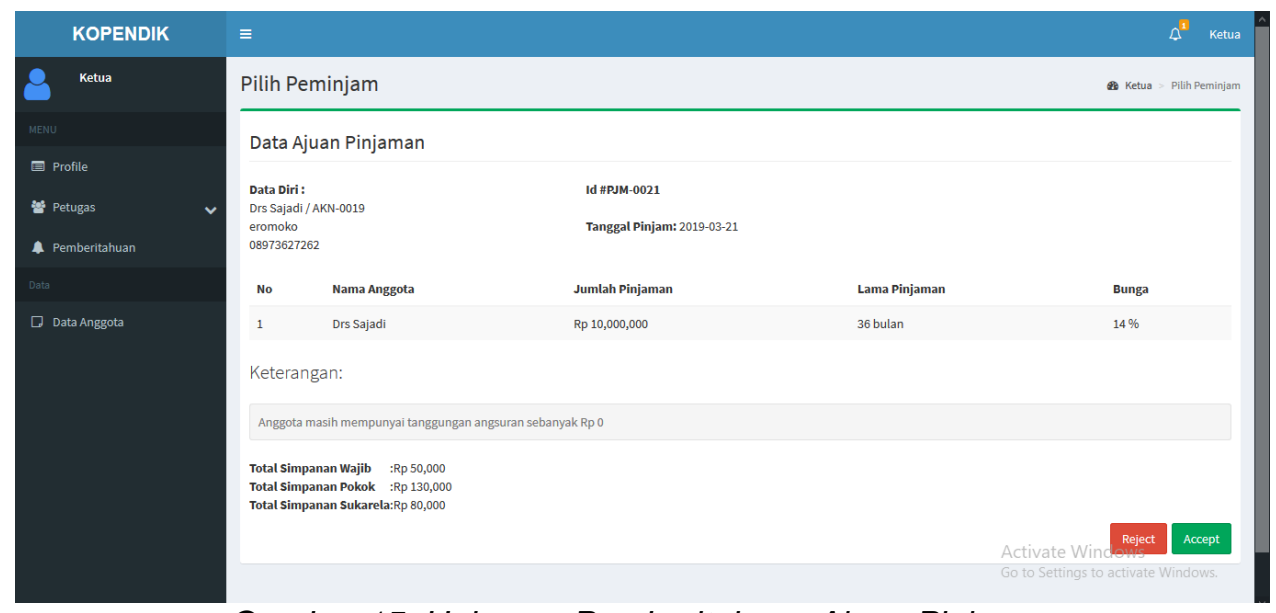

Gambar 15. Halaman Pemberitahuan Ajuan Pinjaman

\subsection{Tahap Pengujian}

Pengujian ini dilakukan dengan menggunakan metode black-box dengan tujuan untuk menjamin kualitas dan juga mengetahui kelemahan dari sistem yang telah dibuat. Berikut hasil pengujian black-box dapat dilihat pada Tabel 1. 


\begin{tabular}{|l|l|l|}
\multicolumn{4}{|c}{ Tabel 1. Hasil Pengujian Black-Box } \\
\hline Input & Output & Kesimpulan \\
\hline Login Petugas & Hak akses petugas & BAIK \\
\hline Login Ketua & Hak akses ketua & BAIK \\
\hline Data Anggota & Pengisian dan edit data anggota & BAIK \\
\hline Data Simpanan & Pengisian simpanan anggota & BAIK \\
\hline Data Pinjaman & Data Pinjaman anggota & BAIK \\
\hline Ajuan Pinjaman & Pengisian ajuan pinjaman anggota & BAIK \\
\hline $\begin{array}{l}\text { Pemberitahuan Ajuan } \\
\text { Pinjaman }\end{array}$ & $\begin{array}{l}\text { Persetujuan ketua terhadap } \\
\text { pengajuan pinjaman anggota }\end{array}$ & BAIK \\
\hline Pembayaran Angsuran & Pembayaran angsuran per bulan & BAIK \\
\hline Laporan & $\begin{array}{l}\text { Laporan per tahun, per anggota, } \\
\text { simpanan dan pinjaman }\end{array}$ & BAIK \\
\hline
\end{tabular}

\subsection{Pengujian Usabilitas}

Dalam pengujian usabilitas ini melibatkan petugas dan ketua koperasi pendidikan wonogiri untuk mengisi kuisioner yang berisi pandangan calon pengguna terhadap sistem. Sebanyak 9 petugas dan 1 ketua koperasi ikut berpatisipasi sehingga diperoleh 10 responden. Perancangan pengujian usabilitas ini menggunakan metode System Usabilty Scale (SUS). SUS sendiri memiliki 10 pertanyaan dan 5 pilihan jawaban. Pilihan jawaban terdiri dari sangat tidak setuju sampai sangat setuju. Rekapitulasi pengujian usabilitas dapat dilihat pada Tabel 2.

Tabel 2. Rekapitulasi Pengujian Usabilitas

\begin{tabular}{|c|c|c|c|c|c|c|c|c|c|c|c|c|c|c|c|c|c|}
\hline \multirow[t]{2}{*}{ No } & \multirow[t]{2}{*}{ Nama } & \multirow{2}{*}{$\begin{array}{c}J K \\
(p / l)\end{array}$} & \multirow[t]{2}{*}{ Jabatan } & \multicolumn{10}{|c|}{ Pertanyaan (p) } & \multirow{2}{*}{$\begin{array}{l}\text { SUM } \\
\text { ganjil }\end{array}$} & \multirow{2}{*}{$\begin{array}{l}\text { SUM } \\
\text { genap }\end{array}$} & \multirow[t]{2}{*}{ Total } & \multirow[t]{2}{*}{ Total $\times 2,5$} \\
\hline & & & & P1 & P2 & P3 & P4 & P5 & P6 & P7 & P8 & P9 & P10 & & & & \\
\hline 1 & $\begin{array}{l}\text { Tunggal } \\
\text { Widodo }\end{array}$ & L & Ketua & 5 & 1 & 5 & 5 & 5 & 2 & 5 & 2 & 4 & 2 & 19 & 13 & 32 & 80 \\
\hline 2 & Etik Agus & $P$ & Petugas & 5 & 2 & 4 & 4 & 4 & 2 & 4 & 2 & 4 & 3 & 16 & 12 & 28 & 70 \\
\hline 3 & $\begin{array}{c}\text { Setya } \\
\text { Widodo }\end{array}$ & L & Petugas & 4 & 2 & 5 & 5 & 5 & 2 & 5 & 2 & 4 & 3 & 18 & 11 & 29 & 72,5 \\
\hline 4 & Sumarno & $\mathrm{L}$ & Petugas & 4 & 2 & 5 & 4 & 4 & 2 & 5 & 2 & 4 & 4 & 17 & 11 & 28 & 70 \\
\hline 5 & Sunardi & $\mathrm{L}$ & Petugas & 4 & 2 & 5 & 4 & 5 & 2 & 4 & 2 & 3 & 3 & 16 & 12 & 28 & 70 \\
\hline 6 & Suranti & $P$ & Petugas & 4 & 2 & 5 & 5 & 5 & 1 & 5 & 2 & 4 & 4 & 18 & 11 & 29 & 72,5 \\
\hline 7 & Suratno & $\mathrm{L}$ & Petugas & 5 & 1 & 5 & 4 & 5 & 2 & 5 & 2 & 4 & 3 & 19 & 13 & 32 & 80 \\
\hline 8 & Sutrisno & $\mathrm{L}$ & Petugas & 4 & 1 & 5 & 5 & 4 & 2 & 4 & 2 & 4 & 3 & 16 & 12 & 28 & 70 \\
\hline 9 & $\begin{array}{l}\text { Agung } \\
\text { Widodo }\end{array}$ & L & Petugas & 4 & 1 & 5 & 3 & 4 & 2 & 5 & 2 & 4 & 3 & 17 & 14 & 31 & 77,5 \\
\hline 10 & Wakimin & $\mathrm{L}$ & Petugas & 5 & 2 & 5 & 4 & 4 & 2 & 4 & 2 & 4 & 3 & 17 & 12 & 29 & 72,5 \\
\hline \multicolumn{17}{|c|}{ RATA-RATA } & 73,5 \\
\hline
\end{tabular}

\section{Keterangan kode:}

Sangat Setuju (SS) : 5

Setuju (ST) : 4

Ragu-Ragu (R) : 3

Tidak Setuju (TS) : 2

Sangat Tidak Setuju (STS) : 1

Untuk perhitungan SUS sendiri untuk pertanyaan ganjil setiap penilaian dari responden dikurangi 1 lalu dijumlahkan. Sedangkan pertanyaan genap setiap nilai dihitung dengan cara 5 dikurangi nilai jawaban responden, lalu dijumlahkan. Kemudian dijumlahkan dari hasil pertanyaan ganjil dan genap lalu dikalikan dengan 2,5. Sehingga hasil pengujian kuisioner dapat dilihat pada Gambar 16. 


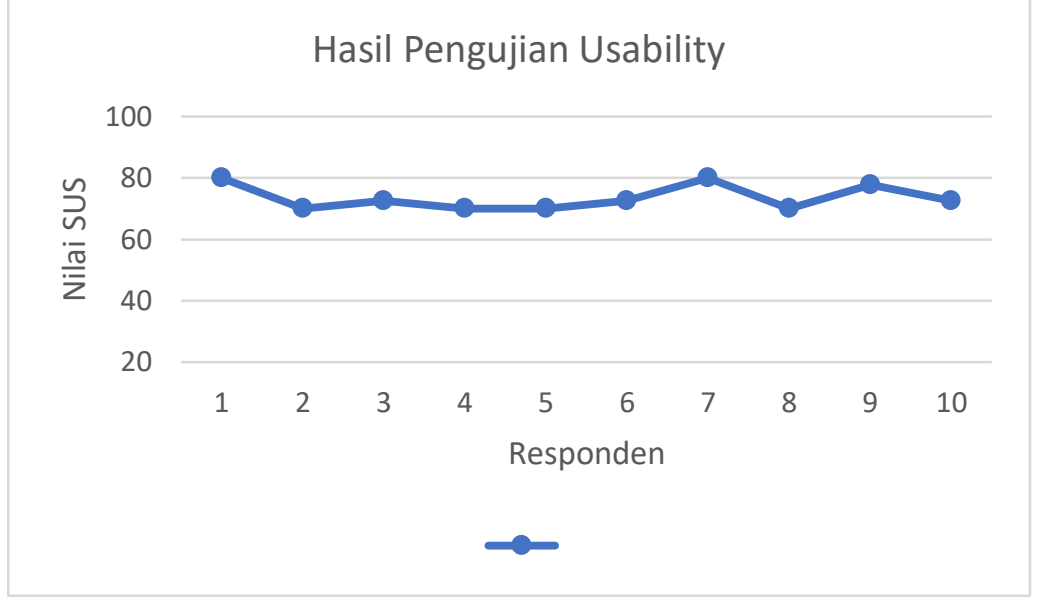

Gambar 16. Grafik Hasil Pengujian Usability

Berdasarkan Gambar 16 diatas dapat disimpulkan hasil pengujian usability ini menghasilkan rata-rata sebesar 73,5 yang berarti sistem ini secara usability dapat diterima dan dapat memberikan manfaat untuk pengguna.

\section{Kesimpulan}

Dari hasil penelitian ini dapat disimpulkan bahwa sistem dirancang sesuai dengan kebutuhan pengguna dimana dalam penerapannya sistem ini lebih difokuskan pada fungsi-fungsi tertentu diantaranya registrasi anggota koperasi, transaksi simpan pinjam serta pembuatan laporan. Dengan adanya sistem baru yang berbasis komputer ini telah dapat mengatasi masalahmasalah yang terjadi pada sistem lama, selain itu pihak koperasi dapat memperoleh beberapa keuntungan antara lain:

1. Sistem dapat menyediakan informasi koperasi secara cepat, tepat dan akurat.

2. Dapat menghemat waktu dalam proses pencarian dan penyimpanan data.

3. Laporan data anggota, transaksi simpanan pinjaman per anggota maupun pertahun dapat diperoleh dengan mudah dan tepat waktu.

\section{Referensi}

[1] Abdilla, Junaedi; Benny S O. Pada Koperasi Spbni Syariah. Progr Stud Manag Inform PKN LKPIA. 2013;2(1):6.

[2] Fadillah MA, Muttaqin FZ, Milly A, Marbun VB. Aplikasi Sistem Informasi Simpan Pinjam Pada Koperasi Usaha Bersama Syari ' Ah At-Tahwil Kota Tangerang. Semin Nas Teknol Inf dan Multimed 2016 [Internet]. 2016;6-7. Available from: http://ojs.amikom.ac.id/index.php/semnasteknomedia/article/view/1322

[3] Anggoro; Dkk. Rancangan Bangun Sistem Informasi Koperasi Simpan Pinjam Guru dan Pegawai pada Koperasi SMK Manggala Tangerang. SENTIKA 2015 (Seminar Nas Teknol Inf dan Komun 2015). 2015;2015(Sentika):213-22.

[4] Nurhanafi A. Sistem Informasi Simpan Pinjam Pada Koperasi Sari Mulyo Kecamatan Ngadirojo. Indones J Netw Secur. 2014;3(3):41-9.

[5] Irnawati O. Metode Waterfall Pada Sistem Informasi Koperasi Simpan Pinjam. Inf Syst Educ Prof [Internet]. 2017;2(1):31 - 40-31 - 40. Available from: http://ejournalbinainsani.ac.id/index.php/ISBI/article/view/612

[6] Anggraeni N, Retnadi E, Kurniawati R. Perancangan Sistem Informasi Simpan Pinjam Di Kud Mandiri Bayongbong. J Algoritm. 2016;9(01):1-11.

[7] Setiyawati E, Sardiarinto. Perancangan Sistem Informasi Berbasis Web Studi Kasus: KSU BMT Al-Ikhwan Yogyakarta. Indones J Comput Inf Technol [Internet]. 2016;1(1):34-41. Available from: http://ejournal.bsi.ac.id/jurnal/index.php/ijcit/article/view/417/317

[8] Syahrial S. Koperasi Berbasis Web Pada Koperasi Unit Desa. Kop Berbas Web Pada Kop Unit Desa. 2016;1(1):80-94.

[9] Bella Hardiyana, S.Kom, M.Kom dan Eko Gusdiono AK. Sistem Informasi Simpan Pinjam (Studi Kasus : Koperasi KSU Tandangsari Tanjungsari Kabupaten Sumedang). 2016; 
[10] Susanti N. Sistem Informasi Simpan Pinjam Badan Keswadayaan Masyarakat Studi Kasus Bkm Sarana Makmur. Simetris J Tek Mesin, Elektro dan Ilmu Komput. 2014;5(1):41.

[11] Prasetyo K, Suharyanto S. Rancang Bangun Sistem Informasi Koperasi Berbasis Web Pada Koperasi Ikitama Jakarta. J Tek Komput. 2019;5(1):119-26.

[12] Astuti D, Devitra J. Dui Astuti, Joni Devitra. Manaj Sist Inf. 2017;2(2):513-32.

[13] Tofik IG, Hartawan GP. Perancangan Aplikasi Koperasi Simpan Pinjam Berbasis Web (Studi Kasus Koperasi Mitra Setia). J IIm IImu Ekon. 2017;5(10):139-51.

[14] Atikah HR, Sukadi. Sistem Informasi Simpan Pinjam Pada Koperasi Wanita. IJNS - Indones J Netw Secur [Internet]. 2013;2(4):26-33. Available from: http://bit.ly/2AjzjRt 